\title{
THE GENERAL POSITION PROBLEM ON KNESER GRAPHS AND ON SOME GRAPH OPERATIONS
}

\author{
Modjtaba Ghorbani, Hamid Reza Maimani \\ Mostafa Momeni, Farhad Rahimi Mahid \\ Department of Mathematics, Faculty of Science \\ Shahid Rajaee Teacher Training University \\ Tehran, 16785 - 136, I.R. Iran \\ e-mail: ghorbani30@gmail.com \\ maimani@ipm.ir \\ momeni.mosi@yahoo.com \\ farhad.rahimi@sru.ac.ir
}

\section{SANDI KLAVŽAR}

Faculty of Mathematics and Physics, University of Ljubljana, Slovenia Faculty of Natural Sciences and Mathematics, University of Maribor, Slovenia Institute of Mathematics, Physics and Mechanics, Ljubljana, Slovenia e-mail: sandi.klavzar@fmf.uni-lj.si

AND

\section{GREGOR Rus}

Faculty of Organizational Sciences, University of Maribor, Slovenia Institute of Mathematics, Physics and Mechanics, Ljubljana, Slovenia

e-mail: gregor.rus4@um.si

\begin{abstract}
A vertex subset $S$ of a graph $G$ is a general position set of $G$ if no vertex of $S$ lies on a geodesic between two other vertices of $S$. The cardinality of a largest general position set of $G$ is the general position number (gpnumber) $\operatorname{gp}(G)$ of $G$. The gp-number is determined for some families of Kneser graphs, in particular for $K(n, 2), n \geq 4$, and $K(n, 3), n \geq 9$. A sharp lower bound on the gp-number is proved for Cartesian products of graphs. The gp-number is also determined for joins of graphs, coronas over graphs, and line graphs of complete graphs.
\end{abstract}


Keywords: general position set, Kneser graphs, Cartesian product of graphs, corona over graphs, line graphs.

2010 Mathematics Subject Classification: 05C12, 05C69, 05C76.

\section{REFERENCES}

[1] B.S. Anand, S.V. Ullas Chandran, M. Changat, S. Klavžar and E.J. Thomas, Characterization of general position sets and its applications to cographs and bipartite graphs, Appl. Math. Comput. 359 (2019) 84-89.

https://doi.org/10.1016/j.amc.2019.04.064

[2] G. Boruzanli Ekinci and J.B. Gauci, The super-connectivity of Kneser graphs, Discuss. Math. Graph Theory 39 (2019) 5-11.

https://doi.org/10.7151/dmgt.2051

[3] B. Brešar and M. Valencia-Pabon, Independence number of products of Kneser graphs, Discrete Math. 342 (2019) 1017-1027. https://doi.org/10.1016/j.disc.2018.12.017

[4] K.N. Chadha and A.A. Kulkarni, On independent cliques and linear complementarity problems (2018). arXiv: 1811.09798

[5] H.E. Dudeney, Amusements in Mathematics (Nelson, Edinburgh, 1917).

[6] P. Erdős, C. Ko and R. Rado, Intersection theorems for systems of finite sets, Q. J. Math. 12 (1961) 313-320. https://doi.org/10.1093/qmath/12.1.313

[7] V. Froese, I. Kanj, A. Nichterlein and R. Niedermeier, Finding points in general position, Internat. J. Comput. Geom. Appl. 27 (2017) 277-296. https://doi.org/10.1142/S021819591750008X

[8] W. Imrich, S. Klavžar and D.F. Rall, Topics in Graph Theory: Graphs and Their Cartesian Product (A K Peters, New York 2008). https://doi.org/10.1201/b10613

[9] M.M. Kanté, R.M. Sampaio, V.F. dos Santos and J.L. Szwarcfiter, On the geodetic rank of a graph, J. Comb. 8 (2017) 323-340. https://doi.org/10.4310/JOC.2017.v8.n2.a5

[10] S. Klavžar, B. Patkós, G. Rus and I.G. Yero, On general position sets in Cartesian grids (2019). arXiv:1907.04535v3

[11] S. Klavžar and I.G. Yero, The general position problem and strong resolving graphs, Open Math. 17 (2019) 1126-1135. https://doi.org/10.1515/math-2019-0088

[12] C.Y. Ku and K.B. Wong, On no-three-in-line problem on m-dimensional torus, Graphs Combin. 34 (2018) 355-364. https://doi.org/10.1007/s00373-018-1878-8 
[13] J.H. van Lint and R.M. Wilson, A Course in Combinatorics (Cambridge University Press, Cambridge, 1992). https://doi.org/10.1017/CBO9780511987045

[14] P. Manuel and S. Klavžar, A general position problem in graph theory, Bull. Aust. Math. Soc. 98 (2018) 177-187. https://doi.org/10.1017/S0004972718000473

[15] P. Manuel and S. Klavžar, The graph theory general position problem on some interconnection networks, Fund. Inform. 163 (2018) 339-350. https://doi.org/10.3233/FI-2018-1748

[16] A. Misiak, Z. Stẹpień, A. Szymaszkiewicz, L. Szymaszkiewicz and M. Zwierzchowski, A note on the no-three-in-line problem on a torus, Discrete Math. 339 (2016) 217-221. https://doi.org/10.1016/j.disc.2015.08.006

[17] T. Mütze and P. Su, Bipartite Kneser graphs are Hamiltonian, Combinatorica 37 (2017) 1207-1219. https://doi.org/10.1007/s00493-016-3434-6

[18] B. Patkós, On the general position problem on Kneser graphs (2019). arXiv:1903.08056v2

[19] M. Payne and D.R. Wood, On the general position subset selection problem, SIAM J. Discrete Math. 27 (2013) 1727-1733. https://doi.org/10.1137/120897493

[20] A. Por and D.R. Wood, No-three-in-line-in-3D, Algorithmica 47 (2007) 481-488. https://doi.org/10.1007/s00453-006-0158-9

[21] S.V. Ullas Chandran and G. Jaya Parthasarathy, The geodesic irredundant sets in graphs, Int. J. Math. Combin. 4 (2016) 135-143. https://doi.org/10.5281/zenodo.826834

[22] M. Valencia-Pabon and J.-C. Vera, On the diameter of Kneser graphs, Discrete Math. 305 (2005) 383-385.

https://doi.org/10.1016/j.disc.2005.10.001

Received 11 March 2019

Revised 13 November 2019

Accepted 20 November 2019 